\title{
Effect of Glycopyrolate on Nausea, Vomiting and Neonatal Outcome During Spinal Anaesthesia for Elective Caesarean Section
}

\author{
Bishwo Ram Amatya', Binita Acharya ${ }^{2}$, Bishwas Pradhan', Modh Nath Marhattha ${ }^{2}$
}

${ }^{1}$ Department of Anaesthesiology, Nepalese Army Institute of Health Sciences; ${ }^{2}$ Department of Anaesthesiology, Institute of Medicine, Kathmandu, Nepal.

\begin{abstract}
Introduction: Glycopyrrolate has better antisialagogue effect and does not cross placental barrier; thereby when given immediately before subarachnoid block for elective caesarean section might reduce incidence and severity of nausea and vomiting without affecting neonatal outcome. Methods: In a prospective randomized double blind placebo controlled study, sixty ASA PS I and II patients undergoing elective caesarean section at term were assigned to receive $1 \mathrm{ml}$ of Inj Normal Saline IV or $1 \mathrm{ml}(0.2 \mathrm{mg})$ of Inj Glycopyrrolate. After subarachnoid block, nausea score was assessed every 5 min during intraoperative period (before and after cord clamping), every $30 \mathrm{~min}$ for initial 4 hour and every 6 hour till $24 \mathrm{hr}$ after surgery. Vomiting was assessed as mild ( $<2$ episodes) and severe ( $>2$ episodes). Apgar scores were recorded $1 \mathrm{~min}$ and $5 \mathrm{~min}$ after birth. Results:The severity of nausea was less in glycopyrrolate group than in normal saline group during intraoperative period ( $p$ value $\leq 0.001$ ) and postoperative period ( $p$ value 0.31 ). During intraoperative and postoperative period, the severity of vomiting was mild in normal saline group where as in glycopyrrolate group there was no vomiting. The incidence of nausea was low in the parturient who received IV glycopyrrolate than those who received normal saline $3.33 \%$ vs. $60 \%$ ( $\mathrm{p}$ value $<0.001$ ) during intraoperative period particularly after cord clamping 0 vs. $53.33 \%$ ( $p$ value $<0.001$ ). There was also reduced incidence of vomiting 0 vs. $13.33 \%$ ( $p$ value 0.03 ) during intraoperative period after cord clamping. All neonates born to the mother participating in the study had satisfactory Apgar score. Conclusions: Injection Glycopyrrolate when given as an IV premedication during spinal anaesthesia for elective caesarean section could reduce both the severity and incidence of nausea and vomiting during intraoperative period particularly after cord clamping without affecting neonatal outcome and causing side effects.
\end{abstract}

Keywords: apgar; caesarean; glycopyrrolate; Nausea; Vomiting

\section{INTRODUCTION}

Nausea \& Vomiting are unpleasant side effects during spinal anaesthesia in Caesarean Section. They cause significant distress to the patient and may have a negative impact on their overall birthing experience. They may also MJSBH Vol 15 Issue 1 Jan- Jun 2016
Correspondence: Bishwo Ram Amatya, Department of Anesthesiology, Shree Birendra Hospital, Chaunni, Kathmandu, Nepal. Email: biswa156@gmail.com 
interfere with the surgical procedure. ${ }^{1}$

The incidence of nausea and vomiting is high during pregnancy because of increased concentration of progesterone in the body. Progesterone causes smooth muscle relaxation leading to impaired motility of esophagus, stomach and small bowel. Progesterone decreases lower esophageal sphincter tone. ${ }^{1}$ The large gravid uterus contributes to the manifestations of upper gastrointestinal symptoms by mechanically compressing the stomach. ${ }^{1}$ Elevated levels of human chorionic gonadotropin (hCG) hormone may play a role in inducing vomiting. ${ }^{1}$

Despite regional anaesthesia being found to be effective, safe and anaesthetic of choice for caesarean sections, nausea and vomiting are still present in a significant number of patients. 2 The incidence of nausea and vomiting during spinal anaesthesia is increased by hypotension, a block higher than fourth thoracic segment and the use of anaesthetic adjunts (e.g., intrathecal opioids). ${ }^{3}$

The aim of the study is to observe the efficacy of glycopyrrolate on preventing nausea, vomiting (incidence and severity) and on neonatal outcome for caesarean section under spinal anaesthesia.

\section{METHODS}

After ethical approval from the Institutional Review Board and Department of Anaesthesiology, Tribhuvan University Teaching Hospital Maharajgunj, Kathmandu, Nepal; a quantitative prospective, randomized, placebo controlled, double blind study was done at preparation room, operating room and post-operative ward. During a study period of 4 months, 60 patients were divided into two groups Group $\mathrm{G}$ as Inj Glycopyrrolate and Group $\mathrm{N}$ as Inj Normal saline with 30 in each group. The sample size was calculated using $\mathrm{p} 1$ MJSBH Vol 15 Issue 1 Jan- Jun 2016 (proportion in population 1 in decibel fraction as 0.10 ), p2 (proportion in population 2 in decibel fraction as $0.40, \alpha$ (Type I error as 0.05 ) and power of the study as 0.80 . Women with singleton pregnancy with ASA physical status I and II scheduled for elective caesarean section at term were taken as inclusion criteria. Parturients with ASA physical status III and above having contraindications for regional anaesthesia, multiple pregnancy, pregnancy induced hypertension, taking drugs with antiemetic properties within $24 \mathrm{hrs}$ before surgery, placenta previa- Grade III and IV, history of motion sickness, history of past PONV, patients with history of gastroesophageal reflux disease, labryinthitis, liver diseases, hyperemesis gravidarum and history of hypersensitivity to the drug to be used in the study were taken as exclusion criteria.

Routine pre-anesthetic evaluation was done one day prior to surgery. Written Informed consent was taken. Patients were kept on fasting for at least 6 hours and premedicated with Tab Ranitidine $150 \mathrm{mg}$ PO at bed time one day before surgery and at 6 am in the morning. In the preparation room baseline systolic blood pressure, diastolic blood pressure and heart rate were recorded. After an intravenous access with an $18 \mathrm{G}$ cannula, a preload of $10 \mathrm{ml} / \mathrm{kg}$ of Ringer's lactate was infused over 15 minute. Patient was then shifted to operation theatre and base line monitoring of systolic blood pressure (SBP), diastolic blood pressure (DBP), heart rate (HR), electrocardiogram (ECG) and oxygen saturation (SPO2) were done and recorded. Patients were randomly assigned to one of two study groups using a sealed envelope technique. Both glycopyrrolate and saline were prepared and given as $1 \mathrm{ml}$ of clear fluid IV either by anaesthesia assistant or nurse on duty 
at operation theatre before performing subarachnoid block and therefore the patient and researcher both were blinded to the randomization.

Subarachnoid block was performed at L2-L3 or L3-L4 space with a 25 gauge spinal needle (Quincke) injecting $2.2 \mathrm{ml}$ of $0.5 \%$ hyperbaric bupivacaine. Heart rate, blood pressure (noninvasive), oxygen saturation was monitored \& recorded every $5 \mathrm{~min}$ interval during the entire operative procedure. Sensory level achieved, as defined by the loss of cold sensation to spirit swab and loss of pin prick sensation, was assessed till adequate sensory level at fourth thoracic (T4) dermatome was obtained. Failure of spinal anaesthesia with conversion to general anaesthesia was excluded from the study. Patients were asked directly using a numerical four point ordinal scale score ${ }^{19}$ at 5 min intervals to grade the severity of nausea during intra-operative period, then every 30 min for $4 \mathrm{hr}$ during early postoperative period and finally every 6 hourly till $24 \mathrm{hr}$ of surgery. Vomiting was assessed as mild ( $<2$ episodes) and severe ( $>2$ episodes). For rescue antiemetics, ondanestron $8 \mathrm{mg} \mathrm{IV}$ was given as first rescue antiemetic if at any time during the study period, irrespective of scoring time, two or more episodes of vomiting occurred. Promethazine $12.5 \mathrm{mg}$ IV was given as second rescue drug for refractory emesis not responding to ondansetron. Oxytocin $20 \mathrm{IU}$ was administered intravenously admixed in $500 \mathrm{ml}$ of RL at the rate of $20 \mathrm{ml} / \mathrm{min}$ initiated after clamping of umbilical cord. Hypotension which was defined as decrease in systolic blood pressure of $20 \%$ or more from baseline values or absolute decrease to less than 100 $\mathrm{mm} \mathrm{Hg}$ was treated by fluid bolus $4 \mathrm{ml} / \mathrm{kg}$. If not corrected, mephentermine $6 \mathrm{mg}$ IV was given and repeated after 3 minutes if hypotension persisted. Phenylephrine $50 \mathrm{mcg}$ MJSBH Vol 15 Issue 1 Jan- Jun 2016
IV was given as a rescue drug if more than 30 $\mathrm{mg}$ of mephentermine was required. Apgar scores were recorded at $1 \mathrm{~min}$ and $5 \mathrm{~min}$ of birth.

Data was collected and were analyzed using statistical package for social sciences (SPSS) version 17 (Microsoft Corporation). Chi square test, Independent $\mathrm{t}$ test and $\mathrm{Z}$ test for proportion were used. $\mathrm{P}$ value less than 0.05 was considered statistically significant.

\section{RESULTS}

1: Severity of Nausea and Vomiting: Severity of nausea was determined by nausea score. As shown in table 1, nausea score was zero (no nausea) in 29 parturients out of 30 (96.66\%) during intraoperative period in Glycopyrrolate group as compared to normal saline group where nausea score zero was present in 12 $(40 \%)$ parturients with $\mathrm{p}$ value $<0.001$. Severity of vomiting was determined by vomiting episodes None of the parturients vomited during intraoperative as well as postoperative period in Group $G$ where as 4 parturients vomited with 1 episode (mild vomiting) during intraoperative period and 1 parturient vomited with single episode during postoperative period in Group N.

Table 1: Severity of nausea; G: Glycopyrolate group; N: Normal Saline group.

\begin{tabular}{|c|c|c|c|c|c|}
\hline $\begin{array}{c}\text { Nausea } \\
\text { score }\end{array}$ & \multicolumn{2}{|c|}{ Group G } & \multicolumn{2}{c|}{ Group N } & $\begin{array}{c}\text { P } \\
\text { value }\end{array}$ \\
\hline & Cases & $\%$ & Cases & $\%$ & \\
\hline 0 & 29 & 96.66 & 12 & 40 & $<0.001$ \\
\hline 1 & 1 & 3.33 & 11 & 36.66 & 0.001 \\
\hline 2 & 0 & 0 & 4 & 13.33 & 0.03 \\
\hline 3 & 0 & 0 & 3 & 10 & 0.07 \\
\hline
\end{tabular}


Table 2: Incidence of nausea during intraoperative period before cord clamping. G: Glycopyrolate, N: Normal Saline

\begin{tabular}{|c|c|c|c|c|c|}
\hline \multicolumn{3}{|c|}{ Group G } & \multicolumn{1}{c|}{ Group N } & $\begin{array}{c}\text { P } \\
\text { value }\end{array}$ \\
\hline Nausea & Cases & $\%$ & Cases & $\%$ & \\
\hline No & 29 & 96.66 & 28 & 93.33 & 1 \\
\hline Yes & 1 & 3.33 & 2 & 6.66 & \\
\hline
\end{tabular}

Table 3: Incidence of nausea during intraoperative period after cord clamping. G: Glycopyrolate, N: Normal Saline

\begin{tabular}{|c|c|c|c|c|c|}
\hline \multicolumn{3}{|c|}{ Group G } & \multicolumn{1}{c|}{ Group N } & $\begin{array}{c}\text { P } \\
\text { value }\end{array}$ \\
\hline Nausea & Cases & $\%$ & Cases & $\%$ & \\
\hline No & 30 & 100 & 14 & 46.66 & $<0.00$ \\
\hline Yes & 0 & 0 & 16 & 53.33 & 1 \\
\hline
\end{tabular}

\section{2: Incidence of Nausea and Vomiting: As} shown in table 2 and table 3; during intraoperative period, in Group G, among 30 parturients only one had nausea before cord clamping, with incidence being 3.33\% where as in Group N, among 30 parturients 18 had nausea with incidence being $60 \%$ and out of which $2(6.66 \%)$ had nausea before cord clamping and $16(53.33 \%)$ had nausea after cord clamping. During postoperative period, none of the parturient had nausea in Group $G$ where as only one had nausea in Group N. None of the parturient in Group $G$ vomited both during intraoperative as well as postoperative period where as in Group N, 4 among 30 parturients vomited after cord clamping with incidence being $13.33 \%$ and only 1 parturient $(3.33 \%)$ vomited during postoperative period.
3: Neonatal outcome: All neonates born to the mother participating in the study had satisfactory Apgar scores as shown in figure 1. Demographic (age wise and sex wise distribution) and ASA physical status wise comparison between two groups were statistically insignificant. In Group G, none of the parturient received antiemetic during the study period where as in Group N, 2 out of 30 parturient $(6.66 \%)$ received ondansteron as rescue antiemetic and got relief. As compared to Group $\mathrm{G}$, the mephentermine requirement in Group N was more (16.66 \% vs. 53.33 \%) which was statistically significant with $p$ value of $<0.001$.

\section{DISCUSSION}

Nausea, retching, and vomiting are common during regional anaesthesia for caesarean deliveries especially when the uterus is exteriorized. ${ }^{4}$ Various pharmacological and non pharmacological methods have been tried for prophylaxis of nausea and vomiting. However, none of the methods whether used alone or in combination have been found to be fully effective. ${ }^{5,6}$ Glycopyrrolate was chosen in our study because of its easy availability, cost effectiveness and more importantly its impermeability to blood brain barrier and placental barrier. ${ }^{7,8}$ This minimizes the risk of

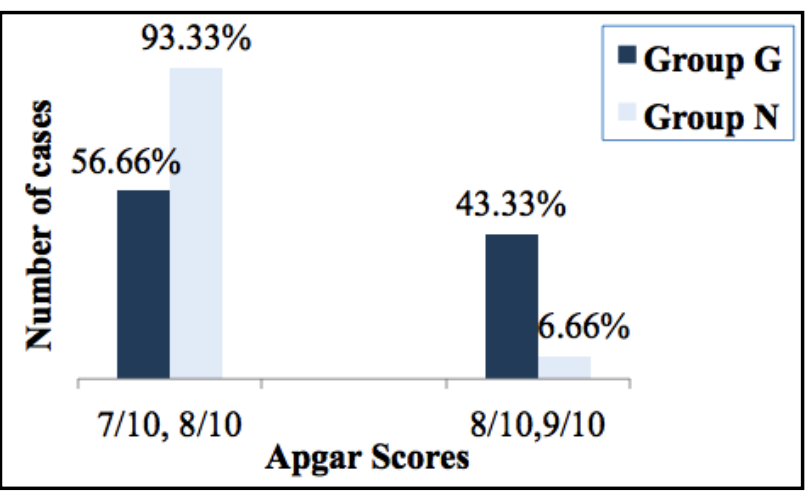

Figure 1:Comparison of Apgar scores in 2 groups, G: Glycopyrolate, N: Normal saline 
sedation and anticholinergic effects in mother and in neonates which are the main concerns for the parturient. The exact mechanism of glycopyrrolate in preventing nausea and vomiting is not known. However, in addition to favorable antisialogogue effect than atropine, it has been found that glycopyrrolate causes heart rate mediated increase in cardiac output and subsequent reduction in hypotension episodes. ${ }^{2,9}$ It also reduces gastric acidity and increases gastric $\mathrm{pH} .^{10,11}$

In our study, during intraoperative period, the severity of nausea and vomiting $33.33 \%$ in glycopyrrolate group vs. $60 \%$ in normal saline group for nausea and 0 vs. $13.33 \%$ for vomiting) was less than that done by Ure D et al $(42 \%$ in glycopyrrolate group vs. $68 \%$ in normal saline group for nausea and $8 \%$ vs. $16 \%$ for vomiting) probably due to less number of cases ( 50 cases) in the study done by Ure D et $\mathrm{al}^{5}$ as compared to 60 cases in our study. The result of our study was similar to that done by Biswas B et al, ${ }^{12}$ where they compared glycopyrrolate with metoclopramide, dexamethasone and normal saline and found that the incidence of nausea and vomiting was less in glycopyrrolate group than in normal saline group (10\% vs. 40\%) during intraoperative period. In our study, the incidence of intraoperative nausea and vomiting had been found to be high after cord clamping which was similar to that done by Albouleish EI et $\mathrm{al}^{13}$ and Chestnut DH et al. ${ }^{14}$ The efficacy of glycopyrrolate as a prophylactic antiemetic during elective caesarean section under spinal anaesthesia of this study was similar to that done by Thakur D et al, ${ }^{15}$ In his study, when Inj glycopyrrolate 0.2 mg IV was used in combination with Inj metoclopramide $10 \mathrm{mg} \mathrm{IV}$, the incidence of nausea during intraoperative period was $3.84 \%$ and vomiting was $0 \%$ that was reduced as MJSBH Vol 15 Issue 1 Jan- Jun 2016 compared to Inj glycopyrrolate alone 10\% (p value 0.38 ) and Inj metoclopramide alone $25.32 \%$ ( $p$ value $<0.001$ ) for nausea and $5 \%$ ( $p$ value 0.30 ) and $2.77 \%$ ( $p$ value 0.08 ) for vomiting respectively. The other study done by Quiney NF, Murphy $\mathrm{PG}^{16}$ had shown that nausea and vomiting which occurred during uterine or peritoneal closure was not associated with hemodynamic instability but rather due to the involvement of parasympathetic efferent in the abdominal discomfort and was reduced by pretreatment with glycopyrrolate. But, in our study, nausea and vomiting was common in parturient receiving normal saline than those receiving glycopyrrolate and was associated with hypotension. Hypotension following spinal anaesthesia is one of the important etiological factors for intraoperative nausea and vomiting in parturient undergoing caesarean delivery. $9,10,11,17,18$

The neonatal outcome as determined by Apgar scores was statistically significant in glycopyrrolate group than in normal saline group but clinically insignificant because both the groups had satisfactory Apgar scores. However, in the study done by Ure D et al, ${ }^{5}$ and Biswas et al, ${ }^{12}$ there were no differences in neonatal Apgar scores between the two groups.

Our study has got few limitations. Firstly, the sample size was relatively small. A study involving a large number of parturient could have given more definite results. Secondly, only the elective cases were included in our study. So, this study had not explained whether glycopyrrolate has significant antiemetic efficacy in parturient undergoing emergency caesarean section or not. Thirdly, the effect of other confounding factors causing nausea and vomiting was not mentioned in this study like uterotonic agents (oxytocin, methyl ergometrine), vagal stimulation like uterine exteriorization, sudden vigorous jerky motion 
and relation of preoperative and postoperative feeding. Fourthly, as nausea score is a subjective scoring system, it was difficult to predict the exact severity of nausea. Fifthly, the neonatal outcome as determined by Apgar scores was statistically significant in the glycopyrrolate group. However, whether glycopyrrolate should be used in every parturient undergoing elective caesarean section to improve neonatal outcome could not be made with this result because both the groups had satisfactory Apgar scores. Lastly, the dose of Inj glycopyrrolate was not mentioned in relation to the body weight.

\section{CONCLUSION}

Inj glycopyrrolate $0.2 \mathrm{mg}$ IV when used as a premedication during spinal anaesthesia for elective caesarean section could significantly reduce severity and incidence of nausea and vomiting particularly during intraoperative period after cord clamping without affecting neonatal outcome.

\section{ACKNOWLEDGEMENT}

I would like to thank Prof Dr Modh Nath Marhatta and Prof Dr Roshana Amatya for their valuable guidance. Similarly, I am also grateful to my co-guides Asoociate Prof Dr Bishwas Pradhan and Asssitant Prof Dr Binita for their continuous guidance.

\section{REFERENCES}

1. Balki M, Carvalho J. Intraoperative nausea and vomiting during caesarean section under regional anaesthesia. International Journal of Obstetric Anaesthesia 2005;14:230-41.DOI. http://dx.doi.org/10.1016/j.ijoa.2004.12.004

2. Ure D, James K, McNeill M, Booth JV. Glycopyrrolate reduces nausea during spinal anesthesia for caesarean section without affecting neonatal outcome. $\mathrm{Br} \mathrm{J}$ Anaesth
1999;82:277-9.DOI. http://dx.doi.org/ $10.1093 / \mathrm{bja} / 82.2 .277$

3. Johnston I. Vasopressor for subarachnoid anaesthesia in obstetrics. Update in anaesthesia 2005;20:1-6.

4. Niebyl J. Nausea and vomiting in pregnancy. N Engl J Med 2010;16:363-16.DOI. http:// dx.doi.org/10.1056/nejmcp1003896

5. Fujii Y. Prevention of emetic episodes during caesarean delivery performed under regional anaesthesia in parturient. Current drug safety 2005;2:25-32.DOI. http:// dx.doi.org/10.2174/157488607779315381

6. Javed S, Hamid S, Amin F, Mahmood K. Spinal anaesthesia induced complication in caesarean section- a review. Journal of Pharmaceutical Sciences and Research 2011;3(10):1530-38.

7. Milkalia A, Kaila T, Kanto J, Iisalo E. Pharmacokinetics of glycopyrronium in parturients. Anaesthesia 1990;45(8): 634-37.DOI. http://dx.doi.org/10.1111/j. 1365-2044.1990.tb14385.x

8. Abboud T, Raya J, Sadri S, Grobler N, Stine L, Miller F. Fetal and Maternal Cardiovascular Effects of Atropine and Glycopyrrolate. Anesth Analg 1983;62:426-30.DOI. http://dx.doi.org/ 10.1213/00000539-198304000-00009

9. Biswas B, Rudra A, Das S, Nath S, Biswas S. Comparative study of Glycopyrrolate, Dexamethasone and Metochlopramide in control of post-operative nausea and vomiting after spinal anaesthesia for caesarean delivery. Indian J. Anaesth 2003;47(3): 198-200.

10. Morgan GE, Mikhail SM, Murray MJ, editors. Clinical Anesthesiology. 4th ed. New York: McGraw Hill Press; 2006. 
11. Racke K, Schworer H. Regulation of serotonin release from the intestinal mucosa. Pharmacol Res 1991;23:13-25.DOI. http:// dx.doi.org/10.1016/S1043-6618(05)80101-X

12. Biswas B, Rudra A, Das S, Nath S, Biswas S. Comparative study of Glycopyrrolate, Dexamethasone and Metochlopramide in control of post-operative nausea and vomiting after spinal anaesthesia for caesarean delivery. Indian J. Anaesth 2003;47(3): 198-200.

13. Abouleish EI, Rashid S, Haque S, Giezentanner A, Joynton P, Chuang AZ. Ondansetron versus placebo for the control of nausea and vomiting during caesarean section under spinal anaesthesia. Anaesthesia 1999;54:479-82.DOI. http://dx.doi.org/ 10.1046/j.1365-2044.1999.00798.x

14. Chestnut DH, Vandewalker GE, Owen CL, Bates JN, Choi W. Adminstration of metoclopramide for prevention of nausea and vomiting during epidural anaesthesia for elective caesarean. Anesthesiology 1987;66:563-66.DOI. http://dx.doi.org/ 10.1097/00000542-198704000-00022

15. Thakur D, Goswami M, Shah H. Combined use of metoclopramide and glycopyrrolate as a prophylactic antiemetic in elective caesarean section under regional anaesthesia. National Journal of Community Medicine 2011;2(1):71-74.
16. Quiney NF, Murphy PG. The pretreatment of Glycopyrrolate on emetic and hypotensive problems during caesarean section conducted under regional anaesthesia. International Journal of Obstetric Anaesthesia 2000;9:66-68.

17. Javed S, Hamid S, Amin F, Mahmood K. Spinal anaesthesia induced complication in caesarean section- a review. Journal of Pharmaceutical Sciences and Research 2011;3(10):1530-38.

18. Yoon HJ, Cho HJ, Lee IH, Jee YS, Kim SM. Comparison of hemodynamic changes between phenylephrine and combined phenylephrine and glycopyrrolate groups after spinal anesthesia for cesarean delivery. Korean Journal of Anaesthesiology 2012;62(1):35-39.DOI. http://dx.doi.org/ $10.4097 / \mathrm{kjae} .2012 .62 .1 .35$

19. Ahmed AB, Hobbs GJ, Curran JP. Randomized placebo controlled trial of combination antiemetic prophylaxis for day case gynaecological laparoscopic surgery. $\mathrm{Br}$ J Anaesth 2000;85(5):678-82.DOI. http:// dx.doi.org/10.1093/bja/85.5.678 